\title{
Residual Stress of Hoop-Wound CFRP Composites Manufactured with Simultaneous Heating
}

\author{
Daisuke Tabuchi*, Takao Sajima ${ }^{1}$, Toshiro Doi ${ }^{1}$, Hiromichi Onikura², \\ Osamu Ohnishi ${ }^{1}$, Syuhei Kurokawa ${ }^{1}$ and Takahiro Miura \\ Department of Intelligent Machinery and Systems, Graduate School of Engineering, \\ Kyushu University, 744 Motooka, Nishi-ku, Fukuoka-shi, Fukuoka 819-0395, Japan \\ ${ }^{1}$ Department of Mechanical Engineering, Faculty of Engineering, Kyushu University, \\ 744 Motooka, Nishi-ku, Fukuoka-shi, Fukuoka 819-0395, Japan \\ ${ }^{2}$ International Research Center for Hydrogen Energy, Kyushu University, \\ 744 Motooka, Nishi-ku, Fukuoka-shi, Fukuoka 819-0395, Japan
}

(Received December 20, 2010; accepted March 7, 2011)

Key words: composite material, filament winding, residual stress, simultaneous heating, finite element method (FEM)

Carbon-fiber-reinforced plastic (CFRP) is used to strengthen high-pressure hydrogen composite vessels. However, the existence of excessive resin between CFRP layers and a drop in the strength of CFRP resulting from the fiber tension during the layer stacking of CFRP composites are the points at issue. To solve them, a curing method using simultaneous heating has been proposed. The purpose of this paper is to evaluate the influence of the simultaneous heating on the residual stress of the CFRP composite. CFRP test specimens were manufactured with simultaneous heating, and strains from their stress releases were measured. As a result, with the simultaneous heating method, the difference in residual stresses between the CFRP inner and outer surfaces is smaller than that with the conventional filament winding (FW) method. We conclude that the simultaneous heating method has an advantage to increase the pressure capacity of composite pressure vessels.

\section{Introduction}

Carbon-fiber-reinforced plastic (CFRP) is used to strengthen high-pressure hydrogen composite vessels. To produce a pressure vessel reinforced by CFRP, the filament winding (FW) method is implemented. In this method, a dry carbon fiber is soaked in a resin bath, where resin impregnates the fiber. This is followed by the stacking of wet fibers on a mandrel. After the stacking, the resin is cured using an autoclave.

*Corresponding author: e-mail: tab@tool-a.mech.kyushu.ac.jp 
However, a drop in the strength of CFRP resulting from the fiber tension during the layer stacking and the existence of excessive resin between CFRP layers are the points at issue. ${ }^{(1-3)}$

To solve them, a curing method using simultaneous heating has been proposed. By heating the resin in the FW process, the resin viscosity decreases, and excessive resin is thought to be eliminated. Moreover, by curing the resin simultaneously in the FW process, the drop in the strength of CFRP resulting from the fiber tension is thought to be reduced.

The purpose of this work was to evaluate the effects of the simultaneous heating method on the residual stress of hoop-wound CFRP. CFRP composite ring specimens were manufactured with simultaneous heating. The strains resulting from the stress release of specimens were measured, and residual stresses were evaluated.

The residual stress measurement test is explained in $\S 2$; the residual stress measurement results are explained in $\S 3$; finally, the discussion is provided in $\S 4$.

\section{Residual Stress Measurement Test}

To evaluate the effects of the simultaneous heating method on the residual stress of hoop-wound CFRP, composite ring specimens were manufactured using an FW machine under different conditions. As winding parameters, fiber tension (5, 15, and $25 \mathrm{~N}$ ) and method of heating (simultaneous heating method and conventional method) were selected. Stress release strains were measured by cutting the specimen into pieces and then residual stresses were evaluated.

\subsection{Manufacturing of specimens}

CFRP composite specimens were manufactured using the FW method. The primary materials used in this study are a high-strength carbon fiber and an epoxy resin. The carbon fiber band T800HB, which contains 12,000 filaments, was manufactured by Toray Industries, Inc. Toray T800HB has a tensile strength of up to 5,490 MPa and an elastic modulus close to $295 \mathrm{GPa}$. The resin is jER ${ }^{\mathrm{TM}}$ 801PN epoxy cross-linked with jERCURE ${ }^{\mathrm{TM}}$ EMI24 curing agent. The carbon fiber band, which is impregnated with the resin, is wound in the hoop direction around an aluminum alloy liner by an FW machine. This machine was uniquely developed by us, and the liner can be heated by hot air. Figure 1 shows a schematic diagram of the FW machine using internal heating. Table 1 shows the mechanical and geometrical properties of the specimen. Figure 2 shows the stacking sequence of the FW method. Figure 3 shows the CFRP ring specimen. As winding parameters, fiber tension (5, 15, and $25 \mathrm{~N}$ ) and method of heating (simultaneous heating method and conventional method) were selected, and six specimens were manufactured. The simultaneous heating method (SIM) is a method in which fiber bands are stacked on a heated liner $\left(80^{\circ} \mathrm{C}\right)$. The conventional method $(\mathrm{CNV})$ is a method in which fiber bands are stacked on a liner at room temperature. After completion of the winding sequence, these composites were cured at $80^{\circ} \mathrm{C}$ for $3 \mathrm{~h}$. After curing, these composite pipes were sliced with a $9.7 \mathrm{~mm}$ axial length using a carbide tool. 


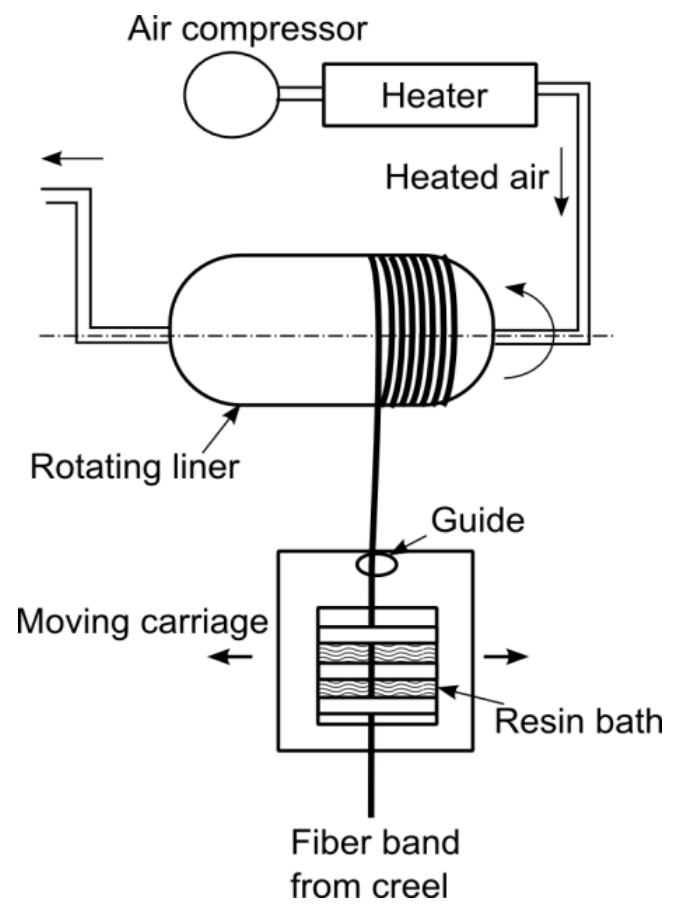

Fig. 1. Schematic diagram of FW machine using internal heating.

Table 1

Properties of specimen.

\begin{tabular}{lc}
\hline Properties of carbon fiber & TORAY T800HB-12K \\
\hline Elastic modulus, $E(\mathrm{GPa})$ & 295 \\
Tensile strength $(\mathrm{MPa})$ & 5,280 \\
Filament diameter $(\mu \mathrm{m})$ & 5 \\
Filament number & 12,000 \\
\hline Properties of epoxy resin & 3.2 \\
\hline Elastic modulus, $E(\mathrm{GPa})$ & 50 \\
Tensile strength $(\mathrm{MPa})$ & \\
\hline Properties of specimen & {$[90]_{8}$} \\
\hline Laminate constitution & 9.7 \\
Specimen width (mm) & 2 \\
Winding pitch (mm) & 99 \\
Outside diameter of liner (mm) & 2 \\
Liner thickness (mm) &
\end{tabular}



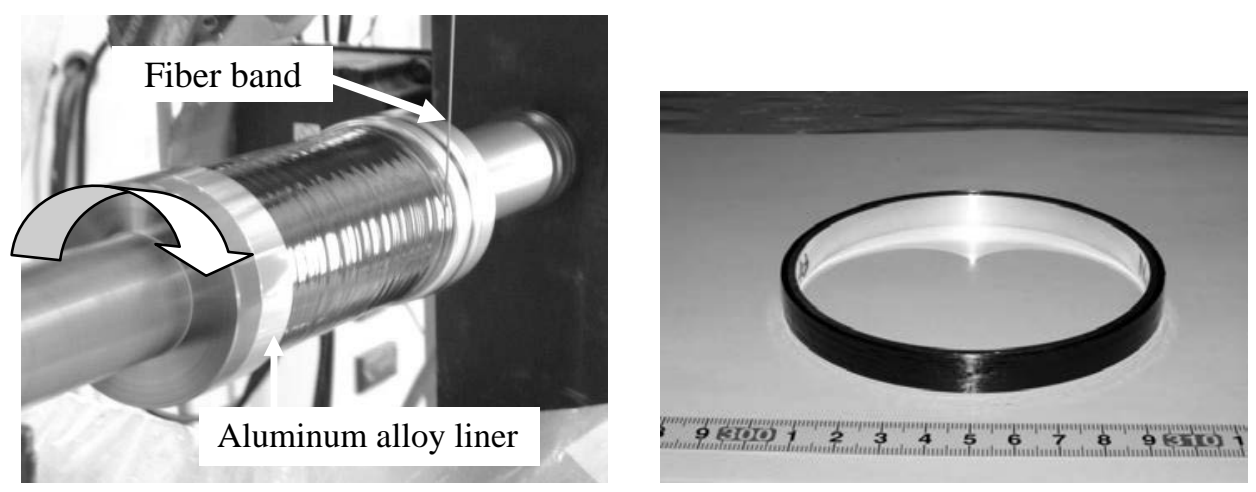

Fig. 2 (left). Stacking sequence.

Fig. 3 (right). CFRP ring specimen.

\subsection{Strain measurement by stress release}

To clarify the residual stresses of CFRP of specimens, strains resulting from stress release were measured. Electrical resistance strain gages were fitted on the CFRP outer surface. Then, strains were measured by cutting the CFRP through the thickness using a thin slitting saw until the ends of the cut ring did not rejoin.

\section{Results}

The hoop residual stresses at the outer surface of the CFRP specimen $\sigma_{\theta}$ were calculated from the stress release strains $\varepsilon_{r=c}$ in accordance with the following equation.

$$
\sigma_{\theta}=-E_{\theta} \cdot \varepsilon_{r=c},
$$

where $E_{\theta}$ is the hoop modulus of each specimen, and it is calculated in accordance with the following equation.

$$
E_{\theta}=V_{\mathrm{f}} \times E,
$$

where $V_{\mathrm{f}}$ is the volume fraction of carbon fibers in CFRP of each specimen (Table 2). The resin modulus is remarkably smaller than the carbon ones, which is ignored here.

Figure 4 shows the hoop residual stresses of each specimen obtained from the above equation. The specimens formed by the CNV method snapped closed as they were cut, and there was a high compressive hoop stress at the outer surface of the CFRP of the specimen. Also, a high tensile hoop stress was expected to be at the inner surface.

The specimens formed by the SIM method were hardly deformed, and it was understood that less hoop residual stress existed in the CFRP of the specimen. It was also understood that the residual stresses at the outer surface of the CFRP of each specimen tended to become tensile in proportion to the fiber tension. 
Table 2

Volume fraction $\left(V_{\mathrm{f}}\right)$ of each specimen.

\begin{tabular}{lccc}
\hline \multicolumn{3}{c}{ Fiber tension } \\
\hline Specimen & $5 \mathrm{~N}$ & $15 \mathrm{~N}$ & $25 \mathrm{~N}$ \\
\hline$V_{\mathrm{f}}$-CNV [\%] & 48.6 & 55.1 & 65.9 \\
$V_{\mathrm{f}}$-SIM [\%] & 59.1 & 66.0 & 68.0 \\
\hline
\end{tabular}

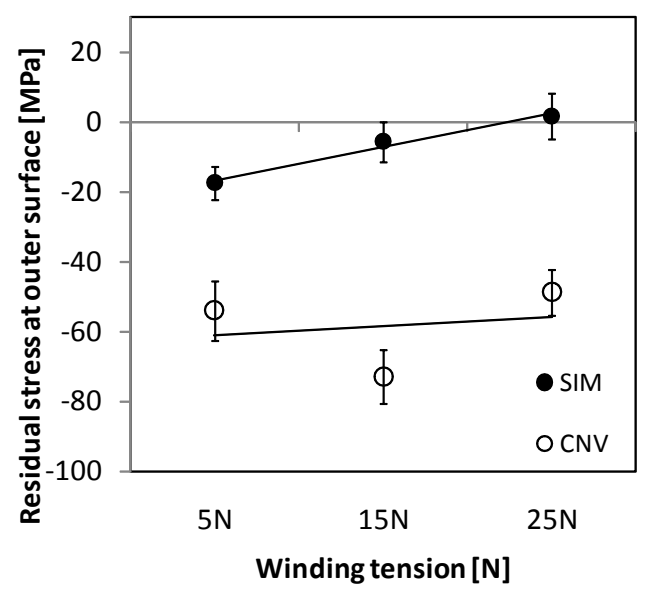

Fig. 4. Experimental hoop stresses at outer surface of specimen.

\section{Discussion}

To verify the results obtained from the above experiments, an analysis of the residual stresses induced at the FW process was carried out by applying the method proposed by Kokan and Gramoll.(4) Figure 5 shows the geometry for the composite specimen. The stress distribution in a composite pipe may be found by decomposing the problem into a number of simpler ones, solving each of them, and superimposing the solutions. In the following section, numerical results were obtained with the following geometry, $a$ $=47.5 \mathrm{~mm}$ and $b=49.5 \mathrm{~mm}$. $c$ was varied according to the winding parameter, that is, $V_{\mathrm{f}}$, cross-sectional area of the carbon fiber, number of stacking, and the winding pitch of each specimen. Table 3 shows them for calculation.

\subsection{Fiber tension stresses}

Faupel and Fisher ${ }^{(5)}$ described a technique to analyze the effects of fiber tension on wire-and-ribbon-wound cylinders. It is applied to calculate residual stresses caused by fiber tension. As the fibers are wound, the underlying material is subjected to a compressive load by fiber tension $\sigma_{T}$. The hoop stress in the CFRP of the specimen $\sigma_{\theta_{-} c}$ is given by 


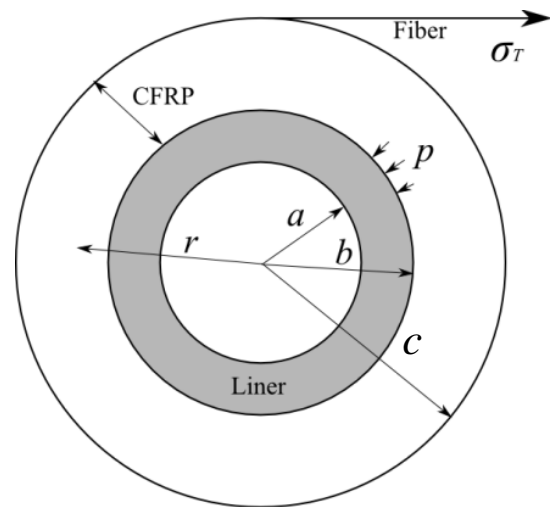

Fig. 5. Geometry of a thick-walled fiber-wound vessel.

Table 3

Outer radius of specimen $c$.

\begin{tabular}{lccc}
\hline & \multicolumn{3}{c}{ Fiber tension } \\
\hline Specimen & $5 \mathrm{~N}$ & $15 \mathrm{~N}$ & $25 \mathrm{~N}$ \\
\hline$c$-CNV [mm] & 51.5 & 51.3 & 51.0 \\
$c$-SIM [mm] & 51.2 & 51.0 & 51.0 \\
\hline
\end{tabular}

$$
\sigma_{\theta_{-} c}=\sigma_{T}\left[1-\left(\frac{r^{2}+a^{2}}{2 r^{2}}\right) \ln \left(\frac{c^{2}-a^{2}}{r^{2}-a^{2}}\right)\right] .
$$

The radial stress in the CFRP of the specimen $\sigma_{r_{-} c}$ is given by

$$
\sigma_{r_{-} c}=-\frac{\sigma_{T}\left(r^{2}-a^{2}\right)}{2 r^{2}} \ln \left(\frac{c^{2}-a^{2}}{r^{2}-a^{2}}\right) .
$$

The hoop stress in the liner of the specimen $\sigma_{\theta l}$ is given by

$$
\sigma_{\theta_{-} l}=-\frac{\sigma_{T}}{2}\left(1+\frac{a^{2}}{r^{2}}\right) \ln \left(\frac{c^{2}-a^{2}}{b^{2}-a^{2}}\right) .
$$

The radial stress in the liner of the specimen $\sigma_{r_{-}}$is given by

$$
\sigma_{r_{-} l}=-\frac{\sigma_{T}}{2}\left(1-\frac{a^{2}}{r^{2}}\right) \ln \left(\frac{c^{2}-a^{2}}{b^{2}-a^{2}}\right) .
$$


Equations (3)-(6) were used to determine the hoop and radial prestresses caused by fiber tension of 5,15 , and $25 \mathrm{~N}$.

\subsection{Heating stresses}

With the CNV method, the specimen liner is heated after layer stacking. Therefore, stresses are generated in the wound carbon fiber by a thermal expansion of the liner. These stresses were analyzed by finite element method (FEM). A two-dimensional axisymmetric structural solid element was used. Table 4 shows the properties used for this analysis.

This curing process involves a rising temperature from room temperature $\left(15^{\circ} \mathrm{C}\right)$ to curing temperature $\left(80^{\circ} \mathrm{C}\right)$. During this time, the resin has not yet gelled, and this is modeled by assuming decreased composite transverse stiffnesses and Poisson's ratios. Therefore, this analysis was carried out with $v_{r \theta}=v_{r z}=0$ and $E_{r}=E_{z}=8.9$ Mpa. Figures 6 and 7 show the FEM results. These figures are plotted with the hoop and radial stresses due to the heating as the vertical axis and the radial position of the CFRP of the specimen as the horizontal axis.

\subsection{Cooling stresses}

After the curing process, stresses are generated by the cooling process. These stresses were analyzed by FEM using the same model as in the case of the heating. Figures 8 and 9 show the FEM results in the case of CNV. Figures 10 and 11 show the FEM results in the case of SIM. The properties used for this analysis are the same as those shown in Table 4.

\subsection{Total stresses}

The total residual stress state is the superposition of these solutions.

Table 4

Properties of CFRP and liner.

\begin{tabular}{ll}
\hline Properties of composite & \\
\hline Hoop elastic modulus, $E_{\theta}(\mathrm{GPa})$ & $V_{\mathrm{f}} \times E$ \\
Radial elastic modulus, $E_{r}(\mathrm{GPa})$ & 8.9 \\
Axial elastic modulus, $E_{z}(\mathrm{GPa})$ & 8.9 \\
Poisson's ratio, $v_{\theta r}, v_{\theta z}$ & 0.34 \\
Poisson's ratio, $v_{r z}$ & 0.02 \\
Coefficient of linear thermal expansion, $\alpha_{r}, \alpha_{z}\left({ }^{\circ} \mathrm{C}^{-1}\right)$ & $70 \times 10^{-6}$ \\
Coefficient of linear thermal expansion, $\alpha_{\theta}\left({ }^{\circ} \mathrm{C}^{-1}\right)$ & $-0.074 \times 10^{-6}$ \\
Density, $\rho(\mathrm{g}$ cm & \\
\hline Properties of liner & 1.57 \\
\hline Elastic modulus, $E(\mathrm{GPa})$ & 73 \\
Poisson's ratio, $v$ & 0.33 \\
Coefficient of linear thermal expansion, $\alpha\left({ }^{\circ} \mathrm{C}^{-1}\right)$ & $23 \times 10^{-6}$ \\
\hline
\end{tabular}



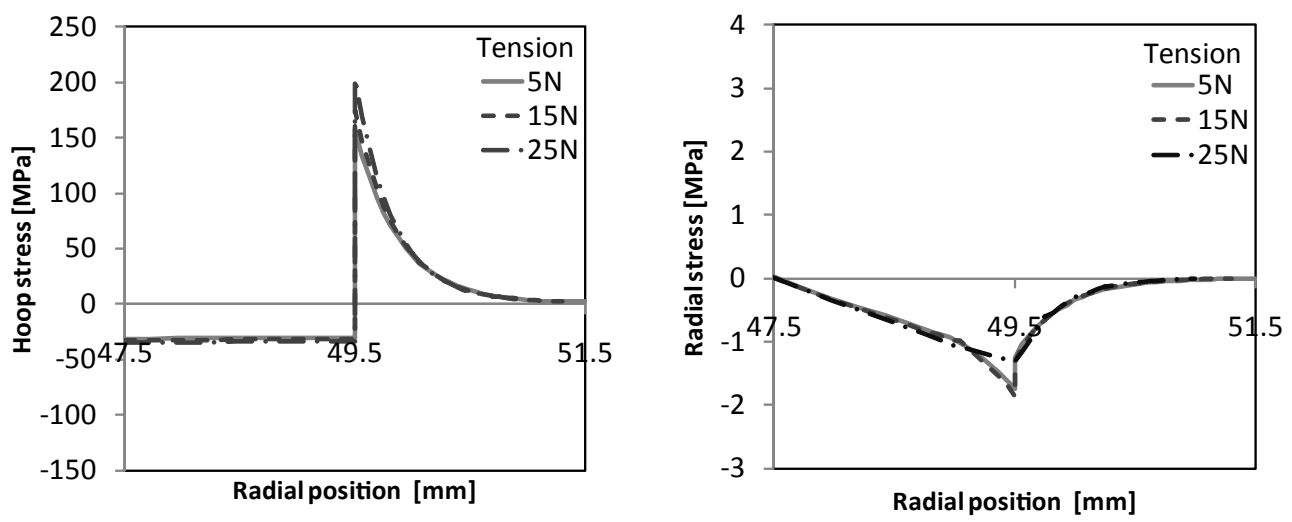

Fig. 6 (left). Hoop stresses due to heating at CNV.

Fig. 7 (right). Radial stresses due to heating at CNV.
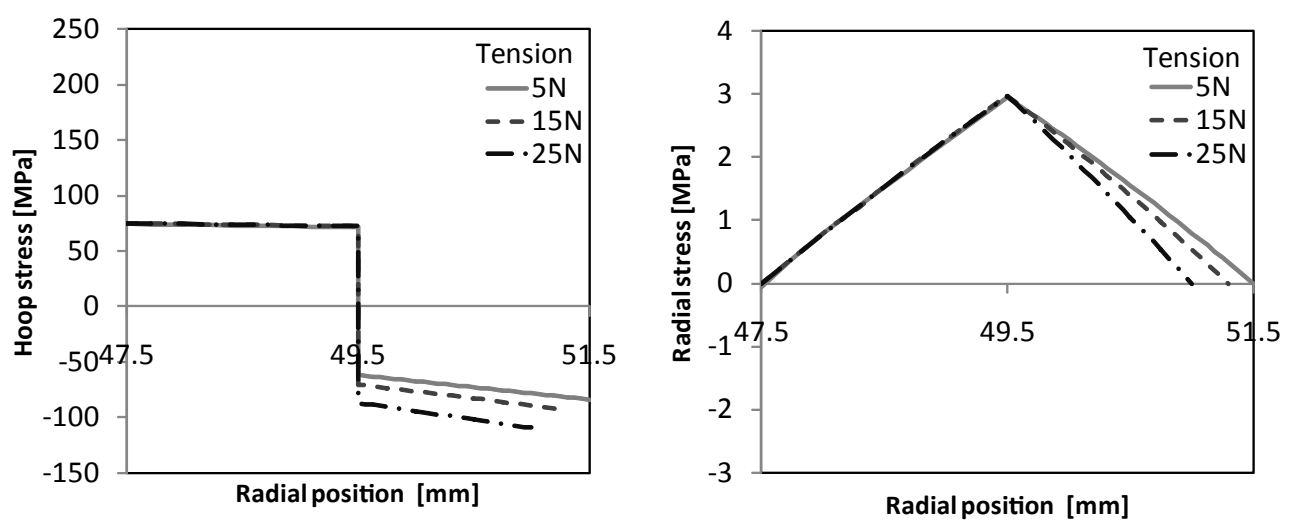

Fig. 8 (left). Hoop stresses due to cooling at CNV.

Fig. 9 (right). Radial stresses due to cooling at CNV.

\subsection{Comparison of analytical results and experimental ones}

The results obtained above were compared with the experimental results in $\S 3$. Figure 12 shows the comparison between calculated data of the hoop stress at the outer surface of the CFRP of the specimen (theory) and the experimental data (exp) for each specimen. This shows that the calculated data are not coincident with the experimental data. 

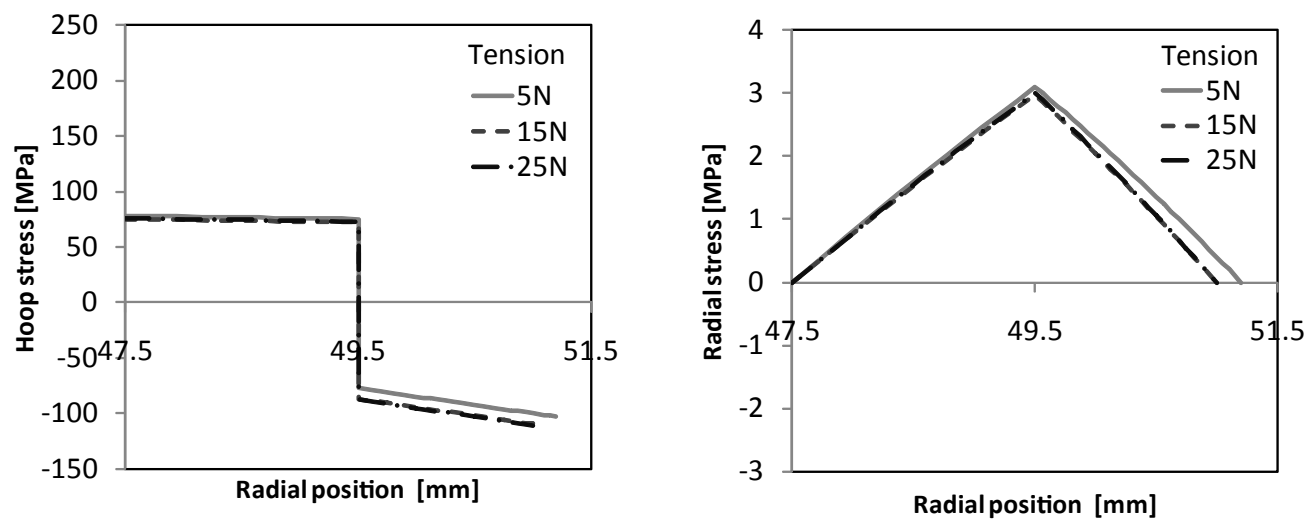

Fig. 10 (left). Hoop stresses due to cooling at SIM.

Fig. 11 (right). Radial stresses due to cooling at SIM.

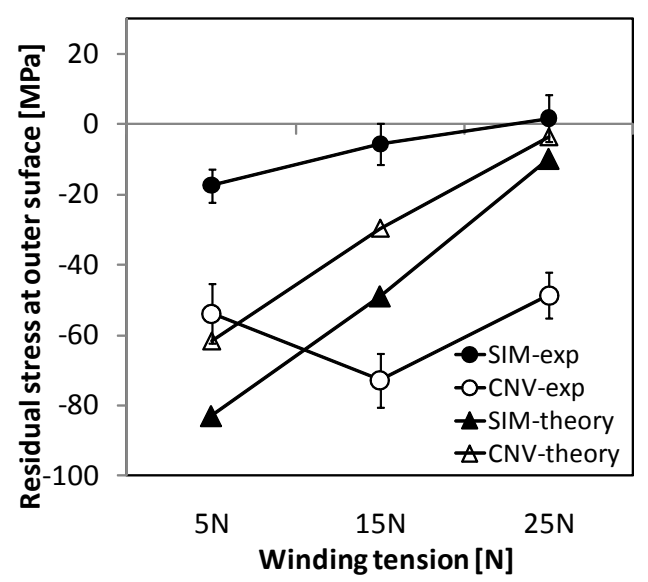

Fig. 12. Comparison of theoretical results with experimental results.

Concerning the case of the CNV method, the calculated values are higher than the experimental values, except for the case of fiber tension of $5 \mathrm{~N}$. In $\S 4.1$, fiber tension $\sigma_{\text {fiber }}$ was used as $\sigma_{T}$ in eqs. (3) to (6). Considering a volume fraction and the rule of mixture, the actual $\sigma_{T}$ may be

$$
\sigma_{T}=\sigma_{\text {fiber }} V_{\mathrm{f}} .
$$

The stresses caused by fiber tension may be smaller than the previous calculated values. 
Therefore, residual stresses were recalculated by substituting eq. (7) into each equation in $\S 4.1$. Figures 13 and 14 show the states of hoop stress and radial residual stress in the case of the CNV. Figures 15 and 16 show the states of hoop stress and radial residual stress in the case of SIM.

Figure 17 shows the comparison between experimental hoop stress at the CFRP outer surface of the specimen (exp) and its calculated values considering $V_{\mathrm{f}}$ (theory).
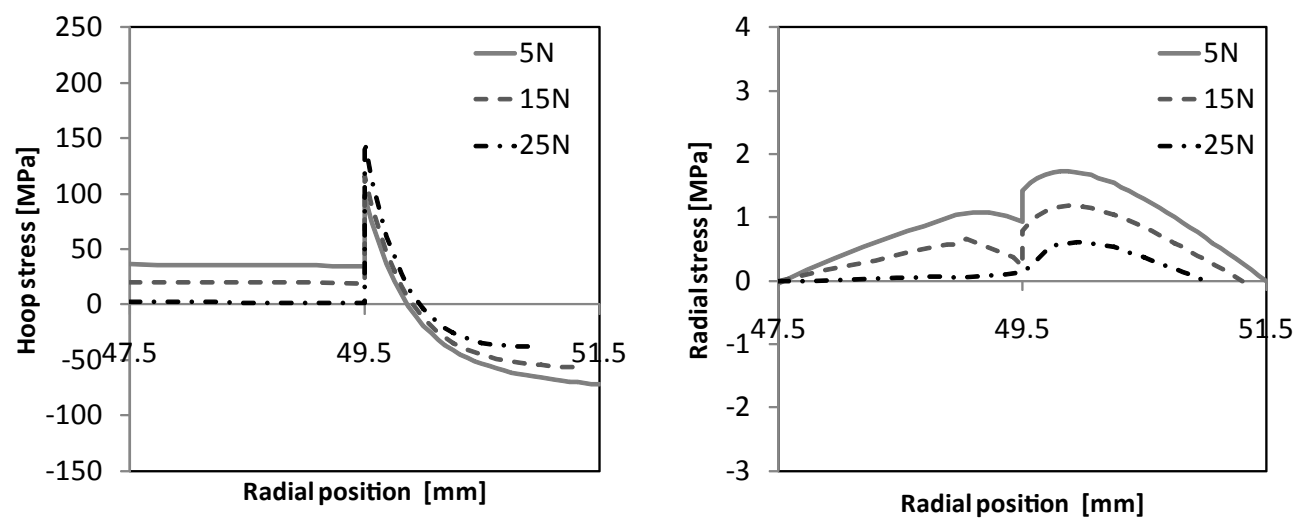

Fig. 13 (left). Total hoop residual stresses at CNV.

Fig. 14 (right). Total radial residual stresses at CNV.
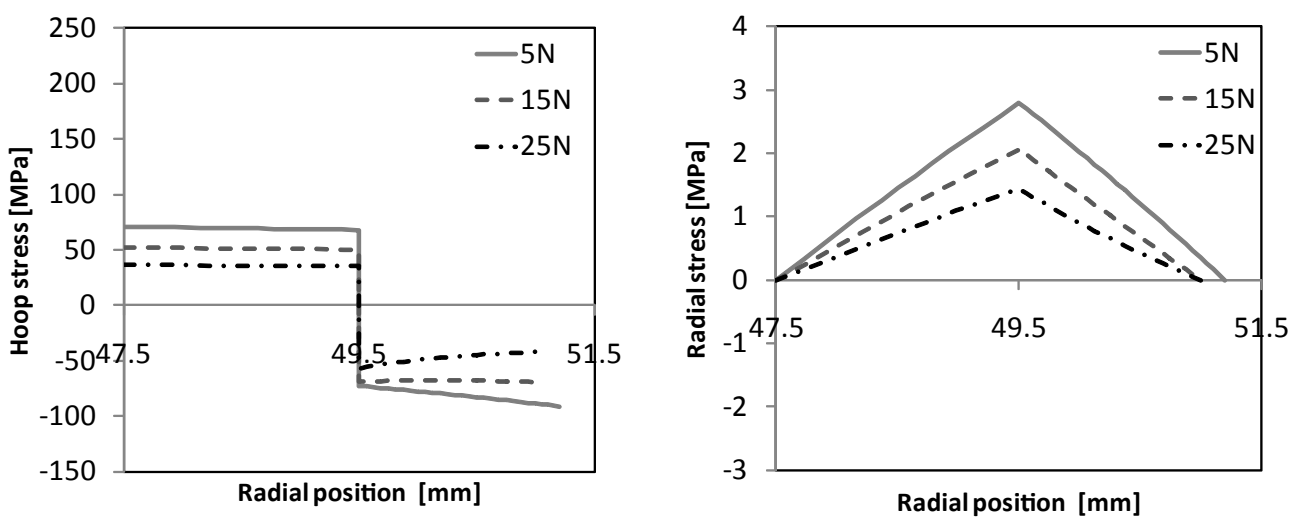

Fig. 15 (left). Total hoop residual stresses at SIM.

Fig. 16 (right). Total radial residual stresses at SIM. 


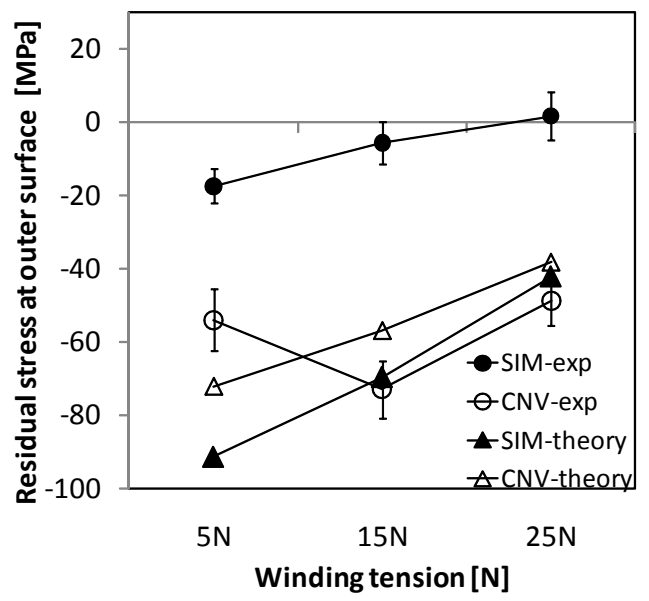

Fig.17. Comparison of theoretical results with experimental results (considering $V_{\mathrm{f}}$ ).

Concerning the case of the CNV method, these values were relatively close. Because of stress release, each specimen snapped closed as they were cut, and there was a high compressive hoop stress at the CFRP outer surface of the specimen, and high tensile hoop stress was expected to be at the inner surface, as shown in Fig. 13. Considering a vessel that is pressurized from the inside, there is a higher hoop tensile stress at its inner part, and its pressure capacity is limited by the strength of its inner part. Thus, these residual stress distributions are thought to have a disadvantage for increasing the pressure capacity of the vessel.

On the other hand, the calculated data are not coincident with the experimental data in the case of the SIM method. Considering these results and Fig. 16, it is understood from Fig. 16 that high tensile stresses occur at the interface between the CFRP and the liner of the specimen. This means that a separation may occur if the adhesive force is smaller than these stresses. A separation was actually observed for the SIM-methodmanufactured specimens.

Thus, the residual stresses were recalculated assuming that the separation occurred. If the separation occurs, the stresses will be balanced throughout the CFRP part. Considering CFRP stress lines (Fig. 15) as straight lines, a shift exists and the stress level becomes zero at the radial middle CFRP position.

Figure 18 shows the residual stresses when the separation occurs. Figure 19 shows the comparison between calculated residual stresses and experimental ones at the outer surface of the specimen. By assuming the separation, the calculated values are in good agreement with the experimental ones. With the SIM method, the difference in residual stresses between the CFRP inner and outer surfaces is smaller than that with the CNV method. It can be explained by the small influence of thermal expansion of the liner. 

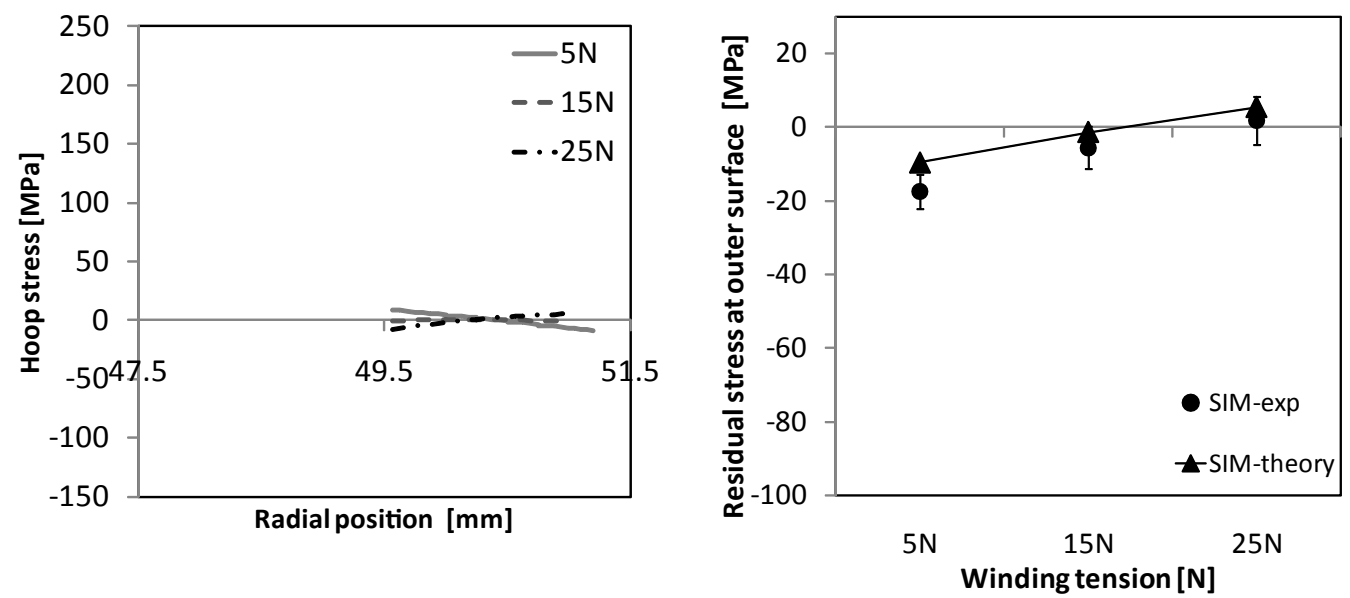

Fig. 18 (left). Total hoop residual stresses at SIM (in separated CFRP).

Fig. 19 (right). Comparison of theoretical results with experimental results at SIM (assuming separation).

Moreover, it is found that the inner hoop stress tends to be compressive and the outer hoop stress tends to be tensile when the fiber tension becomes higher. By applying an adequate fiber tension, compressive inner hoop stress and tensile outer hoop stress at the CFRP will be introduced. This will increase the pressure capacity of the composite pressure vessel.

Here, the effect of the separation on the strength of the CFRP is assumed not to be significant. However, this may cause damage at the interface, and needs to be discussed later.

\section{Conclusions}

To evaluate the effect of the simultaneous heating method on the hoop-wound CFRP residual stress, composite ring specimens were manufactured with an FW machine under different conditions. As winding parameters, fiber tension (5, 15, and $25 \mathrm{~N})$ and method of heating (simultaneous heating method and conventional method) were selected. The stress release strains were measured by cutting the specimen into pieces and then residual stresses were evaluated. Conclusions are the following.

1. Considering the effect of the volume fraction of carbon fibers, the calculated residual stress is in good agreement with the experiments.

2. With the simultaneous heating method, the difference in hoop residual stresses between the CFRP inner and outer surfaces is smaller than that with the conventional FW method. 
3. With the simultaneous heating method, it is found that the inner hoop stress tends to be compressive and the outer hoop stress tends to be tensile when the fiber tension becomes higher. This suggests that for CFRP, compressive inner hoop stress and tensile outer hoop stress can be introduced by applying an adequate fiber tension.

\section{References}

1 M. R. Piggott: Adv. Compos. Mater. 6 (1996) 75.

2 J. W. Lee and C. E. Harris: ASTM STP 1059 (1990) 521.

3 M. R. Etemad, E. Pask and C. B. Besant: Composites 23 (1992) 253.

4 D. Kokan and K. Gramoll: Compos. Eng. 4 (1994) 979.

5 J. H. Faupel and F. E. Fisher: Engineering Design (John Wiley, New York, 1981) p. 739. 